\title{
O IMPACTO DAS RESTRIÇÕES FINANCEIRAS NA PRÁTICA DO CONSERVADORISMO CONTÁBIL: UM ESTUDO DE 2012 A 2016
}

\section{THE IMPACT OF FINANCIAL RESTRICTIONS IN THE PRACTICE OF ACCOUNTING CONSERVATISM: A STUDY FROM 2012 TO 2016}

0 artigo foi aprovado e apresentado no XVIII USP International Conference in Accounting da Faculdade de Economia, Administração e Contabilidade da Universidade de São Paulo, realizado de 25 a 27 de Julho de 2018, em São Paulo (SP).

\section{RESUMO}

O conservadorismo condicional é o reconhecimento, nas informações contábeis, das más notícias mais rapidamente do que o reconhecimento das boas notícias. Ele atua no combate a possíveis atitudes oportunistas do gestor, reduz o custo de monitoramento das partes interessadas e leva a empresa a reconhecer, de forma antecipada, possíveis perdas. Por outro lado, quando uma empresa pratica o conservadorismo, ela gera diferença de retorno futuro e consequentemente ganhos de menor qualidade ou menos sustentáveis. Por conta disso, o conservadorismo seria, em longo prazo, prejudicial à obtenção de recursos de fontes externas. O objetivo desse estudo foi avaliar os efeitos da situação de restrição financeira na prática do conservadorismo condicional. Adicionalmente ao objetivo principal, o modelo empírico adotado permitiu a constatação do conservadorismo nas empresas não restritas financeiramente. A amostra foi composta de empresas listadas na Brasil, Bolsa, Balcão (B3), no período de 2012 a 2016. O modelo empírico utilizado foi o de Ball e Shivakumar (2005), que usa a variação do lucro como proxy e identifica o grau de conservadorismo por meio de ganhos e perdas nos resultados contábeis. A estimação estatística foi realizada através de Mínimos Quadrados Generalizáveis Factíveis (FGLS). Como resultado, encontraram-se indícios que apoiam a conclusão de que o conservadorismo condicional pode ser encontrado nas empresas em geral, sendo estatisticamente menor a probabilidade de encontrá-lo nas empresas com restrição financeira.

Palavras-chave: Conservadorismo Condicional, Conservadorismo, Restrição Financeira.

\begin{abstract}
Conditional conservatism is the recognition, in the accounting information, of bad news more quickly than the recognition of good news. It acts in the struggle against the opportunist attitudes of the manager, reduces the cost of monitoring the stakeholders and leads the company to recognize, in advance, possible losses. On the other hand, when a company practices conservatism, it generates a difference in future returns and consequently lower quality or less sustainable gains. Because of this, conservatism would in the long run be detrimental to getting resources from outside sources. The objective of this study was to evaluate the effects of the financial restraint situation in the practice of conditional conservatism. In addition to the main objective, the empirical model adopted allowed the verification of conservatism in companies not financially restricted. The sample was composed of companies listed in Brazil, Bolsa, Balcão (B3), between 2012 and 2016. The empirical model used was that of Ball and Shivakumar (2005), which uses the profit variation as proxy and identifies the degree of conservatism through gains and losses in the accounting results. The statistical estimation was carried out through Feasible Generalizable Least Squares (FGLS). As a result, evidence has been found to support the conclusion that conditional conservatism can be found in firms in general, with a statistically lower probability of finding it in financially constrained firms.
\end{abstract}

\section{Weverton Eugenio Coelho}

Mestrando em Controladoria e Contabilidade e Graduado em Ciências Contábeis pela Universidade Federal de Minas Gerais (UFMG) Técnico em Contabilidade pelo Serviço Nacional de Aprendizagem Comercial (SENAC-MG) Assistente em Administração na Universidade Federal de Minas Gerais (UFMG). Contato Av. Pres. Antônio Carlos, 6627. Pampulha. Belo Horizonte/MG. CEP: 31270-901

E-mail:weverton@ufmg.br

\section{Eduardo Mendes do Nascimento} Doutor em Controladoria e Contabilidade pela Universidade de São Paulo (USP). Mestre em Ciências Contábeis pela Universidade Federal de Minas Gerais (UFMG). Especialista em Controladoria e Finanças e Graduado em Ciências Contábeis pela Universidade Federal de Uberlândia (UFU). Professor Adjunto na Universidade Federal de Minas Gerais (UFMG). Contato Av. Pres. Antônio Carlos, 6627. PampuIha. Belo Horizonte/MG. CEP: 31270-901 E-mail: e.mn@uol.com.br

João Paulo de Assis Valadares Mestrando em Controladoria e Contabilidade pela Universidade Federal de Minas Gerais (UFMG). Especialista em Gestão Empresarial Faculdade Internacional Signorelli. Graduado em Ciências Contábeis pela Universidade Federal de Minas Gerais (UFMG). Contato Av Pres. Antônio Carlos, 6627. Pampulha. Belo Horizonte/MG. CEP: 31270-901

E-mail: joaopaulovaladares@yahoo.com

Key words: Conditional Conservatism, Conservatism, Financial Restriction. 


\section{INTRODUÇÃO}

A informação contábil tem como objetivo fornecer aos stakeholders subsídios para tomada de decisões, para tanto, devem ser relevantes e fidedignas (COMITÊ DE PRONUNCIAMENTOS CONTÁBEIS, 2011). Para atender esse objetivo informacional, elas são dotadas de diversas características, sendo uma delas o conservadorismo condicional (WATTS, 2003). O conservadorismo condicional é o reconhecimento, nas informações contábeis, das más notícias mais rapidamente do que o reconhecimento das boas notícias (BALL; SHIVAKUMAR; 2005; BASU, 1997). Ele atua no combate a possíveis atitudes oportunistas do gestor, reduz o custo de monitoramento das partes interessadas e leva a empresa a reconhecer, de forma antecipada, possíveis perdas, ou seja, induz o reconhecimento assimétrico das perdas e dos ganhos (WATTS, 2003).

Além disso, outra característica da informação contábil é fornecer subsídios para análise de uma organização (IUDÍCIBUS, 2009). Assim, através dela, é possível verificar: liquidez, solvência, capacidade de investimento, capacidade de pagamento, incluindo possíveis indícios de restrição financeira etc (IUDÍCIBUS, 2009). Com relação à restrição financeira, são possíveis indícios dela: pagar menos dividendos para se autofinanciar com a retenção de lucros; não pagar dividendos por não possuir fluxo de caixa para tal; possuir alto volume de caixa retido decorrente da dificuldade de obter financiamento para possíveis imprevistos; adiar ou extinguir os investimentos em ativos não circulantes, por exemplo, imobilizados e intangiveis, por não possuir folga financeira ou crédito para fazê-lo, dentre outros (FAZARRI; HUBBARD; PETERSEN, 1987; ALMEIDA; CAMPELLO; WEISBACH, 2004; CAMPELLO; GRAHAM; HARVEY, 2010). Observa-se ainda que, quanto às restrições financeiras, a literatura não apresenta consenso absoluto referente a quais elementos devem estar presentes para que se considere que uma empresa está restrita financeiramente (DEMONIER; ALMEIDA; BORTOLON, 2015).

A abordagem dessa pesquisa relaciona as restrições financeiras com o conservadorismo contábil. As pesquisas anteriores sobre esse tema assumiram diferentes aspectos, por exemplo: Biddle, Ma e Song (2011) pesquisaram o conservadorismo e sua relação com a falência, já Lee (2012) investigou a sua relação com a flexibilidade financeira e o acesso ao capital. Em âmbito nacional, Gonzaga e Costa (2009) relacionaram o conservadorismo à política de distribuição de dividendos e Alves e Martinez (2014) analisaram os seus efeitos no Brasil após a adesão à International Financial Reporting Standards (IFRS).

Essas pesquisas, e outras (COELHO, 2007; SANTOS E CALIXTO, 2010; LI, 2015), trouxeram resultados divergentes, tanto quanto à constatação do uso do conservadorismo, quanto ao benefício do seu uso por empresas com restrição financeira, fato este que motiva o presente estudo na investigação dos efeitos dessas restrições na prática do conservadorismo contábil. Além de avançar com a literatura nesse âmbito, essa pesquisa analisou o período regido pela convergência das normas contábeis que se deu a partir de 2010. Sendo assim, o trabalho estabeleceu um parâmetro para ver como se comportou o conservadorismo após a publicação da pesquisa de Demonier, Almeida e Bortolon (2015), o que permitiu uma comparação dos dois trabalhos para os leitores. Por conseguinte, utilizando os dados a partir de 2010, mantiveram-se os parâmetros contábeis hegemônicos, considerando que as demonstrações foram elaboradas utilizando normas contábeis harmonizadas.

Outra importante contribuição desse estudo é analisar o Gap referente à ausência da característica do conservadorismo como condição de aspecto da representação fidedigna nas normas contábeis. Devido à aprovação da primeira revisão da estrutura conceitual para elaboração e apresentação de relatório contábil financeiro, o conservadorismo (prudência) foi retirado da condição de aspecto de representação fidedigna. Justificou-se que ele era inconsistente com a neutralidade, pois subavaliações de ativos e superavaliações de passivos geram registros de desempenho posteriores inflados e tornam-se incompatíveis com a informação que deseja ser neutra (COMITÊ DE PRONUNCIAMENTOS CONTÁBEIS, 2011). Ocorre que, em 2018, o International Accounting Standards Board (IASB) realizou nova mudança no Conceptual Framework, o que reintegrou essa característica da informação contábil (DELOITTE, 2018) e brevemente deverá ser também reintegrada ao Pronunciamento Conceitual Básico. A prudência foi novamente integrada à norma contábil em razão, na visão do IASB, de ela sustentar a neutralidade da informação contábil, pois permite que o julgamento do contrato seja conduzido com cautela em situações que envolvam incertezas (DELOITTE, 2018).

Dessa forma, essa pesquisa contribuiu para verificar se nesse período as demonstrações foram elaboradas sem o atributo do conservadorismo, o que iria de encontro à norma vigente no período. No entanto, o exercício da cautela ao se fazer julgamentos sob condições de incerteza (conservadorismo) pode ser demandado pelos profissionais de contabilidade, ainda que não presente em uma estrutura conceitual. Isso porque as pesquisas empíricas sugerem que a contabilidade é conservadora e foi se tornando ainda mais ao longo do tempo (WATTS, 2003).

A partir do cenário apresentado, formulou-se a seguinte questão: que efeitos as restrições financeiras exercem sobre o conservadorismo condicional após a retirada do conservadorismo das características normativas da contabilidade? Estabelece-se assim que o objetivo principal desta pesquisa é avaliar os efeitos da situação de restrição financeira na prática do conservadorismo condicional. Adicionalmente ao objetivo principal, o modelo empírico adotado permite a constatação do conservadorismo nas empresas não restritas financeiramente.

Para investigar se a empresa apresenta, em seus números contábeis, indícios de práticas do conservadorismo condicional, foi utilizado o modelo de Ball e Shivakumar (2005) e uma adaptação dele feita por Demonier, Almeida e Bortolon (2015). Por sua vez, para classificar a empresa como restrita financeiramente, foi aplicado o critério proposto 
por esses mesmos autores. Dessa forma, a empresa deveria atender cumulativamente aos seguintes critérios: variação positiva do saldo de disponibilidade, variação negativa ou nula de investimento em imobilizados e variação negativa ou nula de distribuição de dividendos (FAZARRI; HUBBARD; PETERSEN, 1987; CLEARY, 1999; ALVES; MARTINEZ, 2014, DEMONIER; ALMEIDA; BORTOLON, 2015).

\section{REVISÃO DE LITERATURA 2.1 Restrição Financeira}

Uma das principais dificuldades do estudo do tema de restrições financeiras é o consenso em relação a quais indicadores devem ser utilizados para a classificação da empresa quanto a restrita financeiramente ou não restrita financeiramente (DEMONIER; ALMEIDA E BARTOLON; 2015). Assim sendo, esta pesquisa utilizou três critérios para classificar as empresas como restritas financeiramente, sendo que eles deveriam ser atendidos cumulativamente.

O primeiro critério utilizado remete à pesquisa de Fazzari, Hubbard e Petersen, (1987). Segundo os autores, que investigaram a relação de investimento, fluxo de caixa e restrição financeira através da política de pagamento de dividendos, empresas que pagam dividendos menores possuem maior grau de restrição financeira. Os pesquisadores argumentam que, devido a situações restritivas, os administradores preferem se autofinanciar com retenção de lucros, haja vista que a captação externa não será financeiramente vantajosa. Além disso, os autores defendem que, muitas vezes, essas empresas não dispõem de fluxos de caixa suficientes para pagar dividendos.

O segundo critério abordado para análise de restrição financeira foi o de Almeida, Campello e Weisbach (2004), que afirmam que a restrição financeira pode ser identificada por meio do volume de caixa armazenado pela empresa. Para eles, para se salvaguardar de imprevistos e não ter que recorrer a fontes externas, empresas restritas financeiramente tendem a manter maiores volumes de valores em caixa.

Essas duas suposições, de que há diminuição do pagamento de dividendos e da alteração no volume de caixa, encontram suporte nos resultados do trabalho de Campello, Graham e Harvey (2010), que analisaram as restrições financeiras durante a crise econômica do ano de 2008 em uma amostra composta de 1.050 diretores financeiros de 39 países. Eles concluíram que empresas com essas restrições, comparativamente a empresas não restritas financeiramente, planejavam reduzir seus investimentos em tecnologia, marketing e emprego. Ademais, elas foram forçadas a reduzir as distribuições de dividendos que haviam sido planejados e utilizar uma parcela de suas reservas de caixa. Em contraponto, nas empresas sem restrição financeira, esses comportamentos não foram observados.

O terceiro e último critério usado para classificação de restrição financeira é o de Cleary (1999), que afirma que empresas com vigor financeiro debilitado evitam a aplicação dos seus recursos próprios em investimentos. Assim, elas mantêm uma folga financeira e diluem riscos futuros, já que possuem à disposição (para utilização) os recursos que estariam investidos. Essa suposição foi igualmente confirmada por um dos resultados da pesquisa de Campello, Graham e Harvey (2010), em que se constatou que empresas restritas financeiramente, por receio da restrição na obtenção de crédito, aceleraram a retirada de fundos de suas linhas de crédito e venderam ativos para gerar receitas. Além disso, 90\% dos pesquisados argumentaram que a restrição financeira restringiu a busca de investimento e mais da metade alega ter cancelado projetos de investimento.

Corrobora esse resultado a pesquisa de Aldrighi e Bisinha (2010), que concluiu que empresas com situação financeira desfavorável, para assegurar "folga financeira" que lhes permita evitar recorrer a empréstimos (que lhes seriam negados ou teriam alto custo), são obrigadas a adiar investimentos. Desses estudos analisados, extrai-se que empresas restritas financeiramente tendem a adotar políticas que visam minimizar o impacto de suas restrições, por estarem cientes de que os números contábeis têm capacidade informacional que lhes é desfavorável (BALL; BROWN, 1968).

Conforme observado, a política de pagamento de dividendos, o volume de caixa e o volume de investimentos são critérios utilizados para definição de restrição financeira. No entanto, individualmente a empresa pode apresentar qualquer um desses critérios por motivos que não estejam relacionados a tal restrição. Por essa razão, somente foi considerada restrita financeiramente a empresa que incorreu nos três critérios simultaneamente (DEMONIER; ALMEIDA; BORTOLON, 2015).

\subsection{Conservadorismo}

O conservadorismo condicional é o reconhecimento das más notícias mais rapidamente do que o reconhecimento das boas notícias (BASU, 1997, BALL; SHIVAKUMAR, 2005). Ele se diferencia do conservadorismo incondicional, em que incondicionalmente subestimam-se valores do patrimônio líquido, em outras palavras, no conservadorismo condicional, dentre as alternativas de mensuração, escolhe-se aquela que gera a menor avaliação patrimonial (BALL; SHIVAKUMAR, 2005; COELHO, 2007). Por sua vez, no conservadorismo condicional, há a antecipação de perdas econômicas não realizadas, cujas estimativas são efetuadas com base em eventos presentes de caráter negativo, resultando no reconhecimento dos fatos contábeis de forma oportunística, assimétrica e beneficiando as perdas (COELHO, 2007).

Por isso, pode-se dizer que, quando encontramos o comportamento da não antecipação de nenhum lucro e a antecipação de todas as perdas, estamos observando o conservadorismo condicional (BLISS, 1924). Por conseguinte, quanto maior a diferença entre o grau de verificação para reconhecimento de ganhos e o grau de verificação para reconheci- 
mento de perdas, maior é o conservadorismo condicional, ou seja, ele pode ser definido como o nível de assimetria para reconhecimento de ganhos e perdas (WATTS, 2003).

A subavaliação dos valores patrimoniais é uma das consequências de se tratar assimetricamente os ganhos e as perdas, por isso, recaem diversas críticas sobre o conservadorismo (WATTS, 2003). A avaliação assimétrica no período atual pode ocasionar variações nas demonstrações dos períodos seguintes, por exemplo, a antecipação do reconhecimento das despesas provoca, nos períodos seguintes, a subavaliação das despesas futuras (WATTS, 2003). Todavia, o conservadorismo pode ser utilizado como um mecanismo para se tratar o problema de agência (LAFOND; ROYCHOWDHURY, 2008).

Nesse sentido, com relação ao Agency Problem, Watts e Zimmerman (1990) esclarecem que a firma é um conjunto de contratos entre os indivíduos e que nem sempre haverá uma harmonia entre os interesses das partes. Nessas relações, a harmonia desses contratos é desbalanceada devido à assimetria informacional, em que o agente pode se beneficiar das informações privilegiadas ou de sua discricionariedade de gestão (por ser o administrador), em detrimento dos interesses do principal (LOPES, 2002).

Logo, à medida que o controle direto do negócio pelos detentores do capital diminui, aumenta-se a assimetria informacional e eleva-se o potencial conflito de agência dela decorrente (LAFOND; ROYCHOWDHURY, 2008). Como consequência, a demanda pelo conservadorismo contábil também aumenta, posto que este diminui a assimetria informacional, caracterizando-se como um mecanismo potencial para resolver o Agency Problem (LAFOND; ROYCHOWDHURY, 2008). Em suma, a separação entre controle e propriedade dá origem aos problemas de agência entre acionistas e administradores, por isso os primeiros demandam o conservadorismo contábil em decorrência dos benefícios a ele associados (LAFOND; ROYCHOWDHURY, 2008).

A pesquisa de Ahmed e Duellman (2007) corroborou esse argumento, ao investigar a relação entre o conservadorismo contábil, a força dos incentivos de monitoramento e as características relacionadas à independência do conselho. Os autores chegaram à conclusão de que, dado que os investidores necessitam de informação para o monitoramento dos gestores, o conservadorismo contábil atua de forma a reduzir os custos de agência das empresas. Porém, o autor salienta que existem outros mecanismos capazes de fazer esse controle e maximizar o valor da empresa.

Em âmbito nacional, diversos trabalhos estudaram o conservadorismo presente nos números contábeis. Utilizando o modelo de Basu (1997), os pesquisadores Da Costa, Lopes e de Oliveira Costa (2006) estudaram como o conservadorismo vinha sendo utilizado no processo de reconhecimento do retorno econômico pelo lucro contábil. A amostra foi composta por empresas argentinas, brasileiras, colombianas, peruanas e venezuelanas, no período de 1995 a 2001. Foi constatado que havia o reconhecimento assimétrico entre más e boas notícias, demonstrando certo grau de conservadorismo condicional.

Esses resultados são confrontados pelos encontrados por Coelho (2007). O autor investigou a prática desse conservadorismo em uma amostra composta por 110 companhias de capital aberto e 2.700 companhias de capital fechado, utilizando dados coletados junto à SERASA, no período de 1995 a 2004. A partir dos modelos de Basu (1997) e Ball e Shivakumar (2005), o autor concluiu que a característica do conservadorismo condicional não é praticada nem pelas companhias abertas nem pelas companhias fechadas.

Coelho e Lima (2008) analisaram se havia o uso desse mesmo atributo pelas companhias de capital aberto da Bovespa no período de 1995 a 2005. Com o intuito de testar se a listagem como emissora de American Depositary Receipts ${ }^{1}$ (ADR) influenciava na prática do conservadorismo condicional, a amostra foi dividida entre companhias emissoras de ADR e companhias não emissoras de ADR. Os autores também investigaram se o sistema contábil influenciava a prática conservadora. Por isso, analisaram tanto os relatórios contábeis elaborados segundo as práticas contábeis do Brasil, (PDB) quanto os relatórios elaborados segundo as práticas dos Estados Unidos (USGAAP - US Generally Accepted Accounting Principles). Por meio de dados coletados do banco de dados Economatica ${ }^{\circledR}$, os pesquisadores chegaram às seguintes conclusões: (a) independente do sistema contábil adotado, não há o uso do conservadorismo condicional; (b) a listagem como emissora de ADR não é suficiente para induzir os gestores à prática do conservadorismo condicional.

Por sua vez, Brito, Lopes e Coelho (2012), ao analisarem o conservadorismo condicional dos bancos que atuavam no mercado financeiros de 1997 a 2010, encontraram resultados opostos aos de Coelho e Lima (2008). Os autores aplicaram o modelo de Basu (1997) e de Ball e Shivakumar $(2005,2006)$ em uma amostra de 260 instituições financeiras bancárias, com controle estatal e com controle privado. Analisando em conjunto todos os bancos, constatou-se que há evidências do uso do conservadorismo condicional. Além de constatar reconhecimento mais oportuno dos ganhos econômicos do que das perdas econômicas, os autores concluíram que os bancos com controle estatal apresentam maiores níveis de conservadorismo condicional do que os bancos com controle privado.

Decerto, o conservadorismo é um conceito amplamente discutido e estudado na contabilidade, que desperta opiniões antagônicas quanto ao benefício do seu uso. Alguns pesquisadores defendem que ele minimiza a assimetria informacional e os conflitos de interesse entre os stakeholders, por conseguinte, é um importante atributo para a gestão da entidade (IUDÍCIBUS, 2009; WATTS, 2003). Todavia, outros defendem que ele conflita com o objetivo da informação relevante e consistente, interferindo na comparabilidade, devendo, consequentemente, ser evitado (HENDRIKSEN; BREDA, 1999; COMITÊ DE PRONUNCIAMENTOS CONTÁBEIS, 2011). 
Assim, espera-se testar se há indícios do uso do conservadorismo condicional na amostra analisada, tanto para empresas classificadas como restritas financeiramente como para as classificadas como não restritas financeiramente. Para tanto, apresenta-se a seguir a relação entre o conservadorismo condicional e a restrição financeira.

\subsection{Conservadorismo e restrição financeira}

O conservadorismo contábil está presente nas demonstrações contábeis e nas práticas contábeis (DOS SANTOS; DA COSTA, 2008). Ele representa uma garantia mínima na percepção de risco por parte do credor, por meio da redução da probabilidade de que os recursos serão distribuídos de forma incorreta para os agentes (PAULO, 2007; DEMONIER; ALMEIDA; BORTOLON, 2015). Esse panorama é baseado na seguinte premissa: ao reconhecer as perdas de forma mais rápida, os resultados são menos otimistas, consequentemente os credores estariam em um ambiente de menor incerteza, uma vez que no conservadorismo as práticas contábeis são mais exigentes com o nível de verificação das boas notícias (PAULO, 2007; DEMONIER; ALMEIDA; BORTOLON, 2015).

Nesse cenário, e segundo Li (2015), o conservadorismo contribui para a redução do custo de captação de recursos de terceiros nos países em que os acordos contábeis são amplamente utilizados. Por consequência, contribui com a diminuição da restrição financeira, já que empresas com esse tipo de restrição teriam maior dificuldade de acesso aos recursos de terceiros a custos baixos (LI, 2015).

Assim, o conservadorismo contábil, ao minimizar a assimetria informacional e o problema de agência, contribui e se relaciona com a redução das restrições financeiras, pois facilitaria o acesso ao crédito por parte da entidade de tal forma que empresas restritas financeiramente tenderiam a adotar o conservadorismo (LI, 2015).

A pesquisa de Biddle, Ma e Song (2011), ao analisar uma amostra de 4.621 empresas listadas nas bolsas de NYSE, AMEX e NASDAQ para os anos fiscais de 1989 a 2007, apresentou evidências de que: o conservadorismo condicional diminui o risco de falência subsequente através de suas propriedades de informação e aumento de caixa, bem como o risco de falência está associado negativamente ao conservadorismo condicional subsequente. Ou seja, os resultados sugerem que o conservadorismo contábil é influenciado pelo risco de falência e vice-versa.

Entretanto o estudo de Lee (2012) investigou se o conservadorismo das demonstrações financeiras estava relacionado à flexibilidade financeira das empresas e a seu acesso ao capital. Para tanto, o autor utilizou-se de duas premissas, a primeira enunciou que "Se o conservadorismo facilitar o monitoramento e a governança pelos fornecedores de capital, eles deveriam estar mais dispostos a ampliar o financiamento e aumentar o acesso das empresas ao capital (LEE, 2011, p. 1)". A segunda, em contraponto à primeira, enunciou que: "porque o conservadorismo leva a uma subavaliação sistemática do patrimônio líquido e enfraquece a consistência do balanço das empresas, também poderia reduzir o acesso das empresas ao capital” (LEE, 2011, p. 1). Dessa forma, o estudo testou essas duas visões antagônicas sobre a ligação entre o conservadorismo e a restrição financeira das empresas:

\footnotetext{
"Os resultados indicam que as empresas com maior conservadorismo nos relatórios financeiros exibem menos flexibilidade na: gestão de liquidez corporativa; em suas decisões de emissão de dívida ou em ações; na sensibilidade de seus investimentos nas restrições de financiamento e em suas políticas de pagamento. No geral, os resultados sugerem que, embora as empresas tenham menor custo de contratação de dívidas, informando de forma conservadora, renunciam a alguma flexibilidade no acesso futuro ao capital e isso afeta suas decisões financeiras (LEE, 2011, p. 1).”
}

A essas mesmas conclusões chegaram Penman e Zhang (2002), que concluíram que, quando uma empresa pratica o conservadorismo, ela gera diferença de retorno futuro e consequentemente ganhos de menor qualidade ou menos sustentáveis. Por conta disso, o conservadorismo seria prejudicial à obtenção de recursos de fontes externas no longo prazo (PENMAN; ZHANG, 2002).

Diante do exposto, observam-se resultados conflitantes quanto ao benefício do uso do conservadorismo condicional por empresas com restrições financeiras, pois alguns estudos ilustram o conservadorismo como benéfico para a organização e outros o apresentam como prejudicial. Em virtude disso, será testada a seguinte hipótese de pesquisa: Ha: Empresas classificadas como restritas financeiramente têm menos probabilidade que as empresas não restritas financeiramente de adotar o conservadorismo condicional.

Em suma, embora diminua o risco de falência, o conservadorismo condicional dificulta o acesso ao capital em longo prazo (PENMAN; ZHANG, 2002; LEE, 2011), o que levaria empresas restritas financeiramente a não o adotar na elaboração de suas demonstrações financeiras. Para analisar a relação do conservadorismo condicional com a restrição financeira, foram analisadas empresas de capital aberto listadas na Brasil Bolsa Balcão (B3), conforme é demonstrado metodologicamente a seguir.

\section{METODOLOGIA}

A pesquisa adotou abordagem quantitativa, ou seja, preocupou-se com o comportamento geral dos acontecimentos, caracterizando-se pelo emprego de instrumentos estatísticos tanto no tratamento dos dados quanto na coleta de informações (RAUPP; BEUREN, 2006). A amostra foi composta de empresas listadas no Brasil, Bolsa, Balcão (B3), no 
período de 2012 a 2016. Ela foi de caráter intencional e foi determinada por disponibilidade de acesso aos dados, haja vista a divulgação deles pelas companhias de capital aberto listadas na B3. Além disso, foram excluídas as empresas do setor financeiro pelas características específicas dessas instituições, que têm regulamentação própria e operam primordialmente alavancadas (PROCIANOY; SCHONORRENBERGER, 2004). Os dados foram coletados do banco de dados Economatica ${ }^{\circledR}$ em junho de 2017.

A pesquisa adotou abordagem positiva da contabilidade. Dessa forma, apoiada em método indutivo e estatístico, procurou estabelecer e testar hipóteses com a finalidade de entender e prever comportamentos, buscar resultados e obter conclusões (IUDÍCIBUS, 2009). Complementarmente Watts e Zimmerman (1990) trazem que a abordagem positiva da contabilidade pode prover informações acerca das políticas contábeis de forma que os stakeholders possam utilizá-las para a tomada de decisões.

Por fim, investigou-se a prática de conservadorismo a partir do modelo de Ball e Shivakumar (2005), e desse modelo adaptado por Demonier, Almeida e Bortolon (2015).

\subsection{Critérios de restrição financeira}

Para se classificar as empresas como restritas financeiramente, os três critérios presentes na revisão de literatura foram empregados. A fundamentação teórica do uso foi apresentada na revisão de literatura, restando a apresentação da forma matemática correspondente a cada um deles, conforme é apresentado na Tabela 1:

Tabela 1: Critérios de identificação de empresas com restrições financeiras

\begin{tabular}{|c|c|}
\hline Critérios & Fundamentações e Equações \\
\hline $\begin{array}{l}\text { Variação positiva } \\
\text { do saldo de } \\
\text { disponibilidade }\end{array}$ & 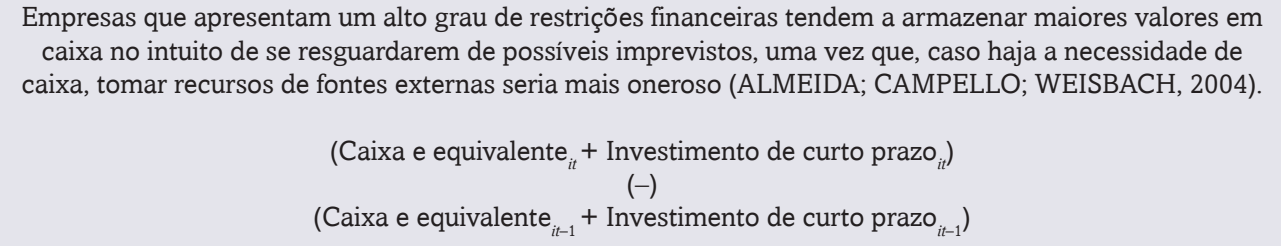 \\
\hline $\begin{array}{l}\text { Variação negativa } \\
\text { ou nula de } \\
\text { investimento em } \\
\text { imobilizados }\end{array}$ & $\begin{array}{l}\text { A empresa com restrição financeira evita fazer investimentos com recursos próprios, para, em caso de } \\
\text { necessidade, não ser obrigada a arcar com altos custos de capital de terceiros (CLEARY, 1999). } \\
\qquad\left(\text { Imobilizado }_{i t}+\text { Depreciação }_{i t}\right)-\left(\text { Imobilizado }_{i t-1}+\text { Depreciação }_{i t-1}\right)\end{array}$ \\
\hline $\begin{array}{l}\text { Variação negativa } \\
\text { ou nula de } \\
\text { distribuição de } \\
\text { dividendos }\end{array}$ & $\begin{array}{l}\text { Empresas com restrições tendem a reter uma fatia maior do lucro, com o intuito de cobrirem possíveis } \\
\text { imprevistos, uma vez que, para essas empresas, o custo do capital próprio é menor do que o custo do capital } \\
\text { externo (FAZZARI; HUBBARD; PETERSEN, 1987) } \\
\left(\frac{\text { Distribuição de Dividendos }_{i t}+J S C P_{i t}}{L L_{i t}}\right)-\left(\frac{\text { Distribuição de Dividendos }_{i t-1}+J S C P_{i t-1}}{L L_{i t-1}}\right)\end{array}$ \\
\hline
\end{tabular}

Fonte: Adaptado de Demonier, Almeida e Bortolon (2015)

Portanto, a empresa analisada apresentou-se como restrita financeiramente se atendesse simultaneamente aos três critérios propostos. A eficiência e a sensibilidade dos critérios de restrição financeira foi verificada por Demonier, Almeida e Bortolon (2015) em uma amostra de controle composta pelas empresas falimentares registradas na Comissão de Valores Mobiliários (CVM). Desse modo, o critério é considerado robusto por apresentar um índice de $75 \%$ de acerto (DEMONIER; ALMEIDA; BORTOLON, 2015).

\subsection{Modelo empírico de Conservadorismo}

Para investigar se a empresa apresenta, em seus números contábeis, indícios de práticas do conservadorismo condicional, foi utilizado o modelo de Ball e Shivakumar (2005), também denominado por Brito, Lopes e Coelho (2012) como modelo de reversão de componentes transitórios do lucro:

Devido à presença do conservadorismo nos números contábeis, há uma tendência de maior persistência dos ganhos do que das perdas. O conservadorismo faz, portanto, com que as acumulações (accruals) sejam assimétricas, visto que as perdas tendem a ser totalmente reconhecidas, ao passo que o mesmo não ocorre com os ganhos. Dessa forma, o período de competência tende a apresentar menor lucro ou evidenciar menor ativo líquido em decorrência da diminuição dos accruals positivos cumulativos (PAULO; ANTUNES; FORMIGONI, 2008, p.51).

Segundo Alves e Martinez (2014), o modelo de Ball e Shivakumar (2005) usa a variação do lucro como variável, 
e identifica o grau de conservadorismo por meio de ganhos e perdas nos resultados contábeis. Ele é representado da seguinte forma:

$$
\Delta L L_{i, t}=\alpha_{0}+\alpha_{1} D \Delta L L_{i, t-1}+\alpha_{2} \Delta L L_{i, t-1}+\left(\alpha_{3} \Delta L L_{i, t-1} * D \Delta L L_{i, t-1}\right)+\varepsilon_{i, t} \text { (Modelo 1) }
$$

Em que:

$\Delta L L_{i, t}$ representa a variação no lucro líquido contábil da empresa i do ano t-1 para o ano t ponderada pelo valor do ativo total no início do ano t; $\Delta L L_{i, t-1}$ representa a variação no lucro líquido contábil da empresa i do ano t-2 para o ano t-1 ponderada pelo valor do ativo total no início do ano t-1; $D \Delta L L_{i, t-1}$ representa uma variável dummy para indicar se existe variação negativa no lucro líquido contábil da empresa i do ano t-1 para o ano t, assumindo valor 1 se $\Delta L L_{i, t}$ $<0$, e 0 nos demais casos; e, $\varepsilon_{i, t}$ é o termo de erro da regressão (PAULO; ANTUNES; FORMIGONI, 2008; BALL; SHIVAKUMAR, 2005)384 company years, with 770 observations relating to private companies and 614 to publicly-quoted companies, for the period 2000 to 2004. The Ball and Shivakumar (2005.

Segundo Paulo, Antunes e Formigoni (2008), a utilização da variável Lucro Líquido como variável explicada fornece a adequada especificação para se identificar componentes transitórios do resultado. Dessa maneira, são esperados os seguintes sinais de coeficientes, conforme Tabela 2:

Tabela 2: Predição dos alfas do modelo e sinal esperado

Coeficientes Predição

$$
\begin{aligned}
& \alpha_{2}<0 \\
& \text { No caso de reconhecimento oportunístico dos ganhos, tornando-os componentes transitórios dos } \\
& \text { resultados que serão revertidos posteriormente. } \\
& \alpha_{2}=0 \quad \text { No caso de diferimento do reconhecimento dos ganhos, até o momento de realização do seu fluxo de } \\
& \text { caixa, tornando-os componentes persistentes do lucro contábil. } \\
& \alpha_{3}<0 \quad \text { No caso de reconhecimento mais oportuno das perdas do que dos ganhos. } \\
& \alpha_{2}+\alpha_{3}<0 \quad \text { No caso de reconhecimento oportunístico das perdas que resulta em decréscimos transitórios no } \\
& \text { resultado e, consequentemente, devem ser revertidas nos períodos seguintes. } \\
& \alpha_{0}, \alpha_{1}
\end{aligned}
$$

\begin{tabular}{|c|c|}
\hline Variável & Conceito \\
\hline$\Delta L L_{i, t}$ & $\begin{array}{l}\text { Variação do lucro líquido contábil da empresa } i \text { do ano } t-1 \text { para todo t escalonado pelo ativo total da empresa } i \\
\text { no início do ano } t \text {. }\end{array}$ \\
\hline$\Delta L L_{i, t-1}$ & $\begin{array}{l}\text { Variação do lucro líquido contábil da empresa } i \text { do ano } t-2 \text { para todo } t-1 \text { escalonado pelo ativo total da empresa } i \\
\text { no início do ano } t-1 .\end{array}$ \\
\hline$D \Delta L L_{i, t-1}$ & $\begin{array}{c}\text { Variável Dummy assumindo valor } 1 \text { para as variações negativas do lucro líquido contábil da empresa } i \text { no ano } t-1 \text {, } \\
\text { e } 0 \text { para as demais variações do lucro líquido contábil da empresa } i \text { no ano } t-1 \text {. }\end{array}$ \\
\hline$D R F_{i, t}$ & $\begin{array}{c}\text { Variável Dummy considerando } 1 \text { para empresa } i \text { do ano } t \text { em condição de restrições financeiras e } 0 \text { para as } \\
\text { demais empresas. }\end{array}$ \\
\hline$\varepsilon_{i, t}$ & Termo de erro da regressão. \\
\hline
\end{tabular}

Fonte: Adaptado de Paulo e Antunes e Formigoni (2008) e Ball e Shivakumar, (2005).

Esse modelo foi posteriormente adaptado pelos próprios autores, que incluíram uma variável dummy para captar o comportamento do conservadorismo entre companhia abertas e fechadas. Demonier, Almeida e Bortolon (2015) substituíram a Dummy de companhias fechadas e abertas por uma Dummy de restrição financeira, assim o modelo apresentou a seguinte forma:

$$
\begin{array}{r}
\Delta L L_{i, t}=\alpha_{0}+\alpha_{1} D \Delta L L_{i, t-1}+\alpha_{2} \Delta L L_{i, t-1}+\left(\alpha_{3} \Delta L L_{i, t-1} * D \Delta L L_{i, t-1}\right)+\alpha_{4} D R F_{i, t}+ \\
\left(\alpha_{5} D R F_{i, t} * D \Delta L L_{i, t-1}\right)+\left(\alpha_{6} D R F_{i, t} * \Delta L L_{i, t-1}\right)+\left(\alpha_{7} D R F_{i, t} * D \Delta L L_{i, t-1} * \Delta L L_{i, t-1}\right)+\varepsilon_{i, t}
\end{array}
$$

(Modelo 2)

Em que:

Tabela 3: Variáveis do Modelo adaptado de Ball e Shivakumar (2005)

Fonte: Adaptado de Demonier Almeida e Bortolon (2015) 
Por fim, Demonier, Almeida e Bortolon (2015) além de incluir a Dummy de restrição financeira adicionaram três variáveis de controle: Tamanho (TAM), Endividamento (ENDIV) e Oportunidade de crescimento (CRESC), sendo tamanho o logaritmo natural do ativo, endividamento a dívida total dividia pelo ativo total e a Oportunidade de Crescimento a razão da variação da receita líquida em t e t-1 pela receita líquida em t-1:

$$
\begin{aligned}
\Delta L L_{i, t}=\alpha_{0}+ & \alpha_{1} D \Delta L L_{i, t-1}+\alpha_{2} \Delta L L_{i, t-1}+\left(\alpha_{3} \Delta L L_{i, t-1} * D \Delta L L_{i, t-1}\right)+\alpha_{4} D R F_{i, t} \\
& +\left(\alpha_{5} D R F_{i, t} * D \Delta L L_{i, t-1}\right)+\left(\alpha_{6} D R F_{i, t} * \Delta L L_{i, t-1}\right)+\left(\alpha_{7} D R F_{i, t} * D \Delta L L_{i, t-1}\right. \\
& \left.* \Delta L L_{i, t-1}\right)+\sum_{n=1}^{k}(1)_{n} V C_{n i}+\sum_{n=1}^{k} \delta_{n} \text { ano }+\varepsilon_{i, t} \text { (Modelo 3) }
\end{aligned}
$$

Em que, além das variáveis já citadas, incluem-se: $V C_{n i}$ que representa as variáveis de controle: Tamanho, Crescimento e Endividamento; e, ano que representa as variáveis Dummy para cada ano. Considerando a hipótese de pesquisa, espera-se que o coeficiente $\alpha_{7}$ seja estatisticamente significativo e apresente sinal positivo para que se confirme a hipótese de que, quando há restrição financeira, a probabilidade de se encontrar o atributo do conservadorismo condicional é menor nas empresas restritas (BALL; SHIVAKUMAR, 2005).

Esse trabalho utilizou, para responder à hipótese de pesquisa, as equações dos modelos (1), (2) e (3), sendo que as análises estatísticas foram efetuadas a um nível de significância de $5 \%$.

\section{APRESENTAÇÃO DOS RESULTADOS E DISCUSSÃO DOS ACHADOS \\ 4.1 Estatística Descritiva}

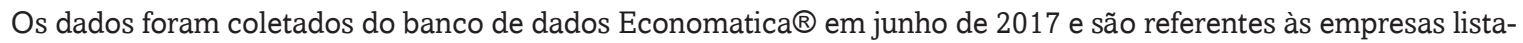
das na B3 no período de 2012 a 2016, sendo excluídas as empresas financeiras, conforme proposto na metodologia. Disso resultou um total de 313 empresas, sendo uma delas eliminada posteriormente por ser considerada um outlier. Dessa forma, restaram 312 empresas. As regressões propostas foram geradas utilizando-se o software Stata $® 12$. A quantidade de empresas restritas e não restritas financeiramente por período é apresentada no Gráfico 1:

Gráfico 1: Empresas restritas e não restritas financeiramente

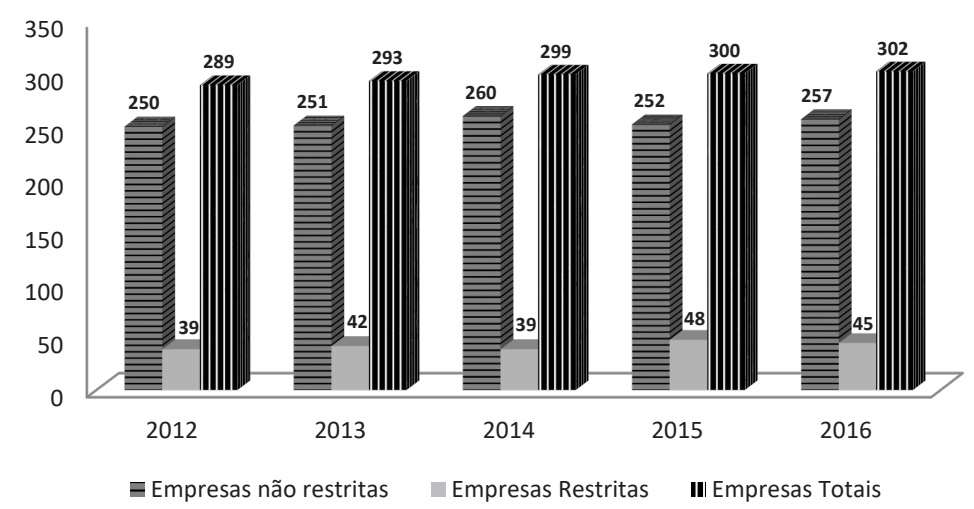

Nota: Empresas restritas financeiramente são aquelas que apresentam simultaneamente: variação positiva do saldo de disponibilidades, variação negativa ou nula de investimento em imobilizados e variação negativa ou nula de distribuição de dividendos.

Fonte: Dados da Pesquisa

Observa-se, no Gráfico 1, um aumento de empresas restritas financeiramente de 2012 a 2016 na ordem de 15\%. Conforme já mencionado, o critério triplo de restrição financeira foi testado em uma amostra de controle, composta pelas empresas falimentares da B3, resultando em um grau de acerto de $75 \%$. Assim, considera-se que o critério de classificação das empresas que apresentam restrição financeira é eficiente (DEMONIER; ALMEIDA; BORTOLON, 2015). Também se observa um aumento no número total de empresas ao longo dos anos. A estatística descritiva das variáveis empregadas nesse estudo, contendo número de observações, média, mínimo, máximo e desvio padrão são apresentadas na Tabela 4: 
Tabela 3: Estatística descritiva das variáveis

\begin{tabular}{|c|c|c|c|c|c|c|}
\hline & Variável & Obs. & Media & Desvio P. & Min & Max \\
\hline Constante & $\Delta L L_{i, t}$ & 1481 & 0,01802 & 0,77416 & $-11,74669$ & 16,91393 \\
\hline$\alpha_{1}$ & $D \Delta L L_{i, t-1}$ & 1483 & & & 0 & 1 \\
\hline$\alpha_{2}$ & $\Delta L L_{i, t-1}$ & 1449 & 0,22120 & 8,26911 & $-11,74669$ & 313,5807 \\
\hline$\alpha_{3}$ & $\Delta L L_{i, t-1} * D \Delta L L_{i, t-1}$ & 1483 & $-0,05509$ & 0,36252 & $-11,74669$ & 0 \\
\hline$\alpha_{4}$ & $D R F_{i, t}$ & 1483 & & & 0 & 1 \\
\hline$\alpha_{5}$ & $D R F_{i, t} * D \Delta L L_{i, t-1}$ & 1483 & & & 0 & 1 \\
\hline$\alpha_{6}$ & $D R F_{i, t} * \Delta L L_{i, t-1}$ & 1483 & 0,00571 & 0,51570 & $-4,45245$ & 16,91393 \\
\hline$\alpha_{7}$ & $D R F_{i, t} * D \Delta L L_{i, t-1} *$ & 1483 & $-0,01640$ & 0,16674 & $-4,45245$ & 0 \\
\hline$V C_{T A M}$ & Tamanho & 1481 & 14,43395 & 1,98689 & 7,52023 & 20,61806 \\
\hline$V C_{E N D}$ & Endividamento & 1384 & 0,28057 & 3,46987 & $-1,16032$ & 109,7711 \\
\hline$V C_{C R E S}$ & Crescimento & 1481 & 1,16931 & 4,16672 & 0,00538 & 70,368 \\
\hline$\delta_{n}$ ano & Dummy Ano de 2012 a 2016 & 1483 & & & 0 & 1 \\
\hline
\end{tabular}

Nota: $\Delta L L_{i, t}$ - Variação do lucro líquido contábil da empresa $i$ do ano $t$-1 para todo $t$ escalonado pelo ativo total da empresa $i$ no início do ano $t$; $\Delta L L_{i, t-1}$ - Variação do lucro líquido contábil da empresa $i$ do ano $t$-2 para todo $t-1$ escalonado pelo ativo total da empresa $i$ no início do ano $t-1 ; D \Delta L L_{i, t-1}$ - Variável Dummy assumindo valor 1 para as variações negativas do lucro líquido contábil da empresa $i$ no ano $t$-1, e 0 para as demais variações do lucro líquido contábil da empresa $i$ no ano $t-1 ; D R F_{i, t}$ - Variável Dummy considerando 1 para empresa $i$ do ano $t$ em condição de restrições financeiras e 0 para as demais empresas

Fonte: Dados da pesquisa

A estatística descritiva presente na Tabela 4 mostra que foram utilizadas quinze variáveis. Foram geradas regressões do tipo dados em painel para se estimar os modelos propostos. Isso porque, em estudos contábeis, usualmente se trabalha com dados referentes a unidades de observação "i”, (empresas, países, etc.) considerados em distintos momentos do tempo " $t$ ", (anos, trimestres, etc.) que, variando ao longo do tempo, constituem um painel de observações (BALTAGI; BRATBERG; HOLMAS, 2005). Além disso, a modelagem em painel permite testar modelos com comportamento mais complexo, modelando diferenças comportamentais entre indivíduos, o que resulta em uma maior eficiência estatística (BALTAGI; BRATBERG; HOLMAS, 2005).

Segundo Bressan, Braga, Bressan e Resende Filho (2012), dentro da modelagem em painel, deve-se selecionar a melhor especificação de modelo dentre os seguintes: Pooled Ols, Efeitos Fixos e Efeitos Aleatórios. Para tanto, deve-se aplicar três testes estatísticos: o teste de Chow, que compara a modelagem de pooled com a modelagem de feitos fixos, o teste de Breusch Pagan, (multiplicador de Lagrange) que compara a modelagem de pooled com a modelagem de efeitos aleatórios e o teste de Hausman, que compara a modelagem de efeitos aleatórios com a modelagem de efeitos fixos (BRESSAN; BRAGA; BRESSAN; RESENDE-FILHO, 2012).

Além da escolha da modelagem, serão feitos testes para validar os pressupostos estatísticos do modelo. Esses testes asseguram que as premissas adotadas para estimação foram atendidas, o que significa dizer que o modelo é passível de ser analisado e não apresenta problemas estatísticos que enviesam seus resultados (BRESSAN; BRAGA; BRESSAN; RESENDE-FILHO, 2012). Nesse sentido, os seguintes testes serão aplicados: teste de multicolinearidade (através do Fator de Inflação da Variância - VIF), estimativa da média do erro, teste de normalidade dos resíduos, teste de forma funcional, teste de autocorrelação e teste de Heterocedastidade etc ${ }^{2}$.

\subsection{Resultado do Modelo Ball e Shivakumar original}

A primeira estimação foi do modelo de Ball e Shivakumar original (modelo 1). O resultado dos testes de Chow e Breush-Pagan, ao nível de significância de 5\%, indicaram que o modelo tradicional deveria ser estimado através da modelagem Pooled. Com relação às demais validações, o modelo apresenta baixa multicolinearidade (VIF 1.02), a média 
do erro foi estimada em zero (5.01e-10) e o teste de normalidade dos resíduos (Doornik-Hansen) indicou que eles não têm distribuição normal. No entanto, segundo o teorema do limite central, os estimadores satisfazem a normalidade assintótica, ou seja, em amostras grandes, eles aproximadamente têm distribuição normal (WOOLDRIDGE, 2010). Como essa amostra tem mais de 1.400 observações, considera-se a flexibilização desse pressuposto (WOOLDRIDGE, 2010). Do mesmo modo, o teste de forma funcional (Reset de Ransey) apresentou que ela omitia variáveis relevantes. Porém, por não ser possível determinar todas as variáveis que influenciam o conservadorismo condicional, esse pressuposto é relaxado e o modelo torna-se passível de ser analisado. Por fim, não foram encontrados indícios de autocorrelação (teste de Wooldridge), todavia, foi constatada a presença de heterocedasticidade (teste de Breush-Pagan / Cook-Weisberg).

Assim, para estimar o modelo e corrigir o problema da heterocedasticidade, utilizou-se a estimação com os erros robustos de White. O resultado desta estimação é apresentado na Tabela 5. Nota-se que toda vez que o resultado indicar um p-valor menor que 0,1, significa que essa variável é estatisticamente significativa no modelo analisado:

Tabela 5: Modelo Ball e Shivakumar (Modelo 1)

\begin{tabular}{|c|c|c|c|c|}
\hline & Variável & Coeficiente & Robust. Erro Padrão & P-valor \\
\hline & Constante & $-0,04772^{\star \star}$ & 0,02318 & 0,040 \\
\hline$\alpha_{1}$ & $D \Delta L L_{i, t-1}$ & 0,09393 ** & 0,03839 & 0,015 \\
\hline$\alpha_{2}$ & $\underline{\Delta L L_{i, t-1}}$ & $-0,00238$ & 0,00309 & 0,440 \\
\hline$\alpha_{3}$ & $\Delta L L_{i, t-1} * D \Delta L L_{i, t-1}$ & $-0,34108$ & 0,25076 & 0,174 \\
\hline
\end{tabular}

Fonte: Dados da pesquisa.

$* * \star$ Significante a $1 \% * \star$ Significante a $5 \%$. ${ }^{*}$ Significante a $10 \%$

A análise da Tabela 5 demonstra que o coeficiente $\alpha_{2}$ não é estatisticamente diferente de zero. Assim, os resultados positivos se tornam componentes persistentes do lucro e não são revertidos nos períodos subsequentes. No entanto, esperava-se que o coeficiente $\alpha_{3}$ fosse estatisticamente significativo, porém ele também não é estatisticamente diferente de zero. Desse modo, considerando modelo original de Ball e Shivakumar há evidência estatística para inferir que não existe o comportamento de se antecipar lucros. Contudo, não há evidências estatísticas para se afirmar que se antecipam as perdas e que elas são revertidas nos períodos subsequentes. Assim, através desse modelo, não podemos concluir que há evidências empíricas de que ocorre o reconhecimento mais oportuno das perdas do que dos ganhos.

\subsection{Resultado do Modelo Ball e Shivakumar modificado}

A segunda estimação foi a do modelo de Ball e Shivakumar modificado (modelo 2). O teste de Chow, o teste Breush-Pagam e o teste de Hausman indicaram que a estimação mais adequada é a estimação por Efeitos Fixos. No tocante às validações, o modelo apresentou multicolinearidade baixa $(\mathrm{VIF}=1,81)$ e a média do erro é zero $(-1,34 \mathrm{e}-9)$. Para a normalidade dos resíduos e a forma funcional, adotam-se os pressupostos já mencionados para análise do modelo original. Ele não apresenta o problema da autocorrelação (teste Wooldridge), mas apresenta indícios da presença de heterocedasticidade (teste de Wald modificado).

Para corrigir o problema da heterocedasticidade, o modelo foi novamente estimado via método de Mínimos Quadrados Generalizados Factíveis ${ }^{3}$ (JUDGE; GRIFFITHS; LUTKEPOHL, 1985; DAVIDSON; MACKINNON, 1993 citados por BRESSAN; BRAGA; BRESSAN; RESENDE-FILHO, 2012). O resultado dessa estimação é apresentado na Tabela 6: 
Tabela 6: Resultado do Modelo de Ball e Shivakumar Modificado (Modelo 2)

\begin{tabular}{|c|c|c|c|c|}
\hline & Variável & Coeficiente & Erro Padrão & P-valor \\
\hline & Constante & 0,00106 & 0,00086 & 0,222 \\
\hline$\alpha_{1}$ & $\underline{D \Delta L L_{i, t-1}}$ & $-0,00584^{\star * \star}$ & 0,00124 & 0,000 \\
\hline$\alpha_{2}$ & $\Delta L L_{i, t-1}$ & $-0,14016^{\star \star *}$ & 0,02989 & 0,000 \\
\hline$\alpha_{3}$ & $\Delta L L_{i, t-1} * D \Delta L L_{i, t-1}$ & $-0,16239 * * *$ & 0,05475 & 0,003 \\
\hline$\alpha_{4}$ & $\underline{D R F_{i, t}}$ & $-0,01107^{\star \star *}$ & 0,00296 & 0,000 \\
\hline$\alpha_{5}$ & $D R F_{i, t} * D \Delta L L_{i, t-1}$ & 0,00195 & 0,00398 & 0,624 \\
\hline$\alpha_{6}$ & $\underline{D R F_{i, t}} * \Delta L L_{i, t-1}$ & $-0,38541^{* * *}$ & 0,11230 & 0,001 \\
\hline$\alpha_{7}$ & $D R F_{i, t} * D \Delta L L_{i, t-1} * \Delta L L_{i, t-1}$ & $0,26900 *$ & 0,14737 & 0,068 \\
\hline
\end{tabular}

Fonte: Dados da pesquisa.

$\star \star \star$ Significante a $1 \% * \star$ Significante a $5 \%$. ${ }^{\star}$ Significante a $10 \%$

Na análise da Tabela 6, encontramos que o coeficiente $\alpha_{2}$ não é estatisticamente igual a zero e apresenta sinal negativo. Isso significa que ocorre o reconhecimento oportuno dos ganhos, tornando-os componentes transitórios dos resultados que serão revertidos posteriormente. Por sua vez, a análise do coeficiente $\underline{\alpha_{3}}$ demonstra que ele é estatisticamente significativo e é menor que zero. Assim, há indícios que apontam para presença do conservadorismo condicional, ou seja, o reconhecimento mais oportuno das perdas do que dos ganhos. Para o mesmo sentido aponta o somatório dos coeficientes $\alpha_{2}$ e $\alpha_{3}$ que apresenta um resultado negativo. Dessa maneira, infere-se que o reconhecimento oportunístico das perdas gera decréscimos transitórios nos resultados que são revertidos posteriormente. Esses resultados são esperados na hipótese que confirma o uso do conservadorismo condicional. Assim, o modelo de Ball e Shivakumar modificado indicou a presença do conservadorismo condicional na análise das empresas em geral.

Com o Modelo de Ball e Shivakumar modificado, que inclui uma dummy interação referente às empresas restritas financeiramente, analisa-se também o conservadorismo condicional nessas instituições. Assim, a análise das empresas classificadas como restritas financeiramente é feita através do coeficiente $\alpha_{7}\left(D R F_{i, t} * D \Delta L L_{i, t-1} * \Delta L L_{i, t-1}\right)$. O coeficiente $\alpha_{7}$ é positivo e estatisticamente significante a $10 \%$, o que evidencia que o reconhecimento assimétrico das perdas é maior nas

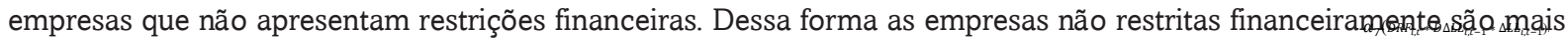
conservadoras do que as empresas restritas financeiramente.

Por conseguinte, considerando o resultado do modelo 2 há indícios para não se rejeitar a hipótese $H a$, ou seja, as empresas restritas financeiramente adotam o conservadorismo condicional em um menor nível que as empresas não restritas financeiramente. Portanto, os resultados também indicam que as empresas restritas antecipam menos as más notícias do que as empresas não restritas.

\subsection{Resultado do Modelo Ball e Shivakumar com variáveis de controle}

Por fim, a terceira estimação foi a do modelo de Ball e Shivakumar, considerando as variáveis de controle (modelo 3). O teste de Chow, o teste Breush-Pagam e o teste de Hausman indicaram que a estimação mais adequada é a estimação por Efeitos Fixos. No tocante às validações, o modelo apresentou multicolinearidade moderada (VIF=2,28) e média do erro zero (-1,37e-10). Para a normalidade dos resíduos e a forma funcional, adotam-se os pressupostos mencionados no modelo original. Além disso, ele apresentou autocorrelação (teste Wooldridge) e heterocedasticidade (teste de Wald modificado).

Dessa forma, o modelo foi novamente estimado via método de Mínimos Quadrados Generalizados Factíveis, dessa vez, considerando o ajuste para a autocorrelação e o ajuste para a heterocedasticidade. O resultado da estimação é apresentado na Tabela 7: 
Tabela 7: Resultado do Modelo de Ball e Shivakumar Modificado com variáveis de controle (Modelo 3)

\begin{tabular}{|c|c|c|c|c|}
\hline & Variável & Coeficiente & Erro Padrão & P-valor \\
\hline & Constante & 0,00326 & 0,00712 & 0,647 \\
\hline$\alpha_{1}$ & $D \Delta L L_{i, t-1}$ & 0,00099 & 0,00139 & 0,475 \\
\hline$\alpha_{2}$ & $\Delta L L_{i, t-1}$ & $-0,16745^{\star \star \star}$ & 0,03735 & 0,000 \\
\hline$\alpha_{3}$ & $\Delta L L_{i, t-1} * D \Delta L L_{i, t-1}$ & $-0,11934^{\star \star}$ & 0,05891 & 0,043 \\
\hline$\alpha_{4}$ & $D R F_{i, t}$ & $-0,00344$ & 0,00354 & 0,331 \\
\hline$\alpha_{5}$ & $D R F_{i, t} * D \Delta L L_{i, t-1}$ & $-0,01064^{\star \star}$ & 0,00447 & 0,017 \\
\hline$\alpha_{6}$ & $D R F_{i, t} * \Delta L L_{i, t-1}$ & $-053688^{* * *}$ & 0,07438 & 0,000 \\
\hline$\alpha_{7}$ & $D R F_{i, t} * D \Delta L L_{i, t-1} * \Delta L L_{i, t-1}$ & $0,35137^{\star \star \star}$ & 0,11891 & 0,003 \\
\hline$V C_{T A M}$ & Tamanho & $-0,0009$ & 0,00456 & 0,842 \\
\hline$V C_{E N D}$ & Endividamento & $0,00220^{\star \star *}$ & 0,00071 & 0,002 \\
\hline$V C_{C R E S}$ & Crescimento & $-0,01263^{\star * \star}$ & 0,00350 & 0,000 \\
\hline
\end{tabular}

Fonte: Dados da pesquisa.

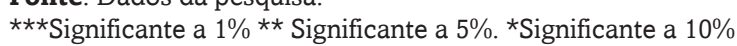

A Tabela 7 apresenta o modelo estatístico com as variáveis de controle. Observa-se que a única variável de controle que não apresentou significância estatística foi a variável Tamanho. Com relação ao coeficiente $\alpha_{2}$ ele é estatisticamente significativo e negativo, indicando, assim como no modelo adaptado, que os ganhos são antecipados e revertidos posteriormente. Brito, Lopes e Coelho (2012) explicam que isso pode indicar receitas extraordinárias em certos períodos que não se repetem ao longo dos anos.

A análise dos coeficientes $\alpha_{3},\left(\alpha_{2}+\alpha_{3}\right)$ e $\alpha_{7}$ seguem os resultados da estimação do modelo 2 . Assim, confirma-se o uso do conservadorismo condicional pelas empresas em geral e confirma-se que o reconhecimento assimétrico das perdas é maior nas empresas que não apresentam restrições financeiras. Dessa forma as empresas não restritas financeiramente são mais conservadoras do que as empresas restritas financeiramente.

Por conseguinte, considerando o resultado do modelo 3, há indícios para não se rejeitar a hipótese $H a$, ou seja, as empresas restritas financeiramente reconhecem, de forma menos assimétrica, do que as empresas não restritas, as más notícias.

\subsection{Discussão dos achados}

Os resultados que foram reportados sinalizam que, ao analisarmos as empresas da amostra em conjunto, encontra-se a característica do conservadorismo condicional, que é expressa no reconhecimento assimétrico das perdas e dos ganhos (BALL; SHIVAKUMAR, 2005). Nesse ínterim, Watts (2003) explica que a contabilidade utiliza-se do conservadorismo condicional como uma forma de enfrentar o risco moral decorrente das informações assimétricas. Por sua vez, Huijgen e Lubberink (2002) consideram que a antecipação de perdas tem como uma de suas causas a proteção aos gestores. Isso porque eles estão sujeitos aos riscos de litígio decorrentes dos contratos que utilizam os números contábeis (HUIJGEN; LUBBERINK, 2002). Os resultados também demonstraram que as empresas restritas financeiramente adotam o conservadorismo condicional em um nível menor que as empresas não restritas financeiramente.

Esses resultados podem ser explicados pelas pesquisas de Lee (2012) e Penman \& Zhang (2002), que consideraram, dentre outros motivos, que o conservadorismo prejudica a obtenção de recursos nas empresas com restrição financeira por gerar ganhos de menor qualidade em longo prazo. Isso talvez sinalize o porquê de as empresas restritas financeiramente terem decidido não antecipar o reconhecimento de prováveis perdas.

Uma das principais contribuições desse estudo é demonstrar que a mudança nos padrões contábeis, ocorrida com a revisão do pronunciamento conceitual básico, que culminou na retirada do conservadorismo como aspecto da representação fidedigna, não foi incentivo suficiente para que as demonstrações deixassem de ser conservadoras (COMITÊ DE PRONUNCIAMENTOS CONTÁBEIS, 2011). Porventura, isso pode estar relacionado ao fato de que, mesmo não constante na estrutura conceitual básica, os contadores não deixaram de considerá-lo como um aspecto relevante da informação contábil.

Ademais, a reintegração do exercício da cautela, ao se fazer julgamentos sob condições de incerteza (conservadorismo), no Conceptual Framework, ocorrida no ano de 2018 (DELOITTE, 2018), concomitante com os resultados 
apontados pelos modelos econométricos, sinalizam indícios que corroboram a afirmação de Watts (2003) de que a contabilidade é conservadora e continuará conservadora.

Do ponto de vista econômico, pode-se concluir que estar inserido em uma situação de restrição financeira é incentivo para que se adotem práticas menos conservadoras, já que foi constatado que empresas restritas financeiramente adotam o conservadorismo condicional em um nível menor que as empresas não restritas. Portanto, a situação de restrição financeira implica a diminuição da antecipação assimétrica de perdas econômicas.

Por fim, observa-se que, se por um lado o conservadorismo condicional mitiga os riscos gerenciais através de seu requisito de verificabilidade assimétrica, (WATTS, 2003), por outro, ele conflita com a consistência no sentido de que induz a falta de comparabilidade, posto que não são uniformes os padrões de sua implantação (HENDRIKSEN; BREDA, 1999). Por isso, é necessário entender os benefícios e malefícios associados ao seu uso, para que os objetivos informacionais dos relatórios financeiros sejam atingidos e eles possam ser utilizados na tomada de decisões, nos julgamentos de alocação financeira, nas análises de solvência etc (PAULO, 2007).

\section{CONCLUSÃO}

Essa pesquisa buscou averiguar o conservadorismo condicional nas empresas restritas financeiramente e adicionalmente nas empresas não restritas financeiramente. A amostra foi composta de 312 empresas listadas na Brasil, Bolsa, Balcão (B3), no período de 2012 a 2016. Foi adotado um critério triplo para se determinar a situação de restrição financeira: variação positiva do saldo de disponibilidade, variação negativa ou nula de investimento em imobilizados e variação negativa ou nula de distribuição de dividendos (ALVES; MARTINEZ, 2014; CLEARY, 1999; FAZZARI; HUBBARD; PETERSEN, 1987).

Para avaliar o conservadorismo condicional, utilizou-se do modelo de Ball e Shivakumar (2005), e uma adaptação desse modelo realizada por Demonier, Almeida e Bortolon (2015). Esse modelo usa a variação do lucro como proxy o que permite identificar o grau de conservadorismo por meio da persistência ou reversão dos ganhos e perdas nos resultados contábeis.

Concluiu-se que há indícios da utilização do conservadorismo condicional pelas empresas presentes na amostra. Além disso, como hipotetizado, as empresas restritas financeiramente têm menor probabilidade de adotar o conservadorismo condicional do que as empresas não restritas financeiramente.

Por fim, são duas as principais implicações práticas deste estudo. A primeira é a discussão do uso do conservadorismo e a constatação do seu uso como característica da informação contábil. Essa característica, segundo o IASB, não conflita com a informação que deseja ser neutra e contribui com o aspecto de representação fidedigna (DELOITTE, 2018). Todavia, se for considerado que o aspecto assimétrico do conservadorismo condicional (WATTS, 2003) é prejudicial à informação contábil, os resultados devem ser interpretados como um indício da necessidade de mudança no comportamento dos elaboradores das demonstrações financeiras, ou ainda como um indicativo da necessidade de reavaliação das normas, que resulta em uma informação conservadora.

A segunda implicação deste estudo é o panorama do impacto informacional do conservadorismo condicional nas demonstrações financeiras e os benefícios e malefícios associados ao seu uso. Desse modo, considerando as discussões atuais de que o IASB tem tratado durante o processo de reformulação da estrutura conceitual, nas quais o conservadorismo tem sido revisto, o entendimento de como esse fenômeno ocorre nas empresas torna-se relevante.

Como sugestão para pesquisas futuras, pode-se utilizar outro modelo econométrico na mesma amostra, por exemplo, o modelo de Basu (1997), e estudar comparativamente os resultados obtidos nos dois modelos. Pode-se ainda adotar outro critério de restrição financeira. Por fim, pode-se adotar o mesmo modelo adicionando-se variáveis de controle que identifiquem o segmento da B3 ao qual a empresa pertence. Com isso, poderá ser constatado se o segmento de listagem influência no nível ou no uso do conservadorismo condicional.

\section{REFERÊNCIAS}

AHMED, A. S.; DUELLMAN, S. Accounting conservatism and board of director characteristics : An empirical analysis. Journal of Accounting and Economics, v. 43, p. 411-437, 2007.

ALDRIGHI, D. M.; BISINHA, R. Restrição financeira em empresas com ações negociadas na Bovespa. Revista Brasileira de Economia, v. 64, n. 1, p. 25-47, 2010.

ALMEIDA, H.; CAMPELLO, M.; WEISBACH, M. S. The cash flow sensitivity of cash. The Journal of Finance, v. LIX, n. 4, p. 1777-1804, 2004.

ALVES, J. DE S.; MARTINEZ, L. A. Efeitos da adoção das IFRS do conservadorismo contábil das sociedades de grande porte. Advances in Scientific and Applied Accountings, v. 7, n. 2, p. 224-243, 2014.

BALL, R.; BROWN, P. An empirical evaluation of accounting income numbers. Journal of Accounting Research, p. 159-178, 1968.

BALL, R.; SHIVAKUMAR, L. Earnings quality in UK private firms: comparative loss recognition timeliness. Journal of Accounting and Economics, v. 39, p. 83-128, 2005.

BALTAGI, Badi H.; BRATBERG, Espen; HOLMÅS, Tor Helge. A panel data study of physicians' labor supply: the case of Norway. Health Economics, v. 14, n. 10, p. 1035-1045, 2005. 
BASU, S. The conservatism principle and the asymmetric timeliness of earnings. Journal of Accounting and Economics, v. 24, p. 3-37, 1997.

BIDDLE, G. C.; MA, M. L. Z.; SONG, F. M. Accounting conservatism and bankruptcy risk. The 2011 Financial Accounting and Reporting Section Midyear Meeting. American Accounting Association. p. 27-29, 2011.

BLISS, J. H. Management through accounts. New York: The Ronald Press Company, 1924.

BRESSAN, Valeria Gama Fully; BRAGA, Marcelo Jose; BRESSAN, Aureliano Angel; RESENDE FILHO, Moises de Andrade. O seguro depósito induz ao risco moral nas cooperativas de crédito brasileiras?: um estudo com dados em painel. Revista Brasileira de Economia, v. 66, n. 2, p. 167-185, 2012.

BRITO, Giovani Antonio Silva; LOPES, Alexsandro Broedel; COELHO, Antonio Carlos Dias. Conservadorismo nos lucros contábeis dos bancos no Brasil: a influência do controle estatal. Revista Universo Contábil, v. 8, n. 4, p. 19-39, 2012.

CAMPELLO, M.; GRAHAM, J. R.; HARVEY, C. R. The real effects of financial constraints : Evidence from a financial crisis. Journal of Financial Economics, v. 97, n. 3, p. 470-487, 2010.

CLEARY, S. The relationship between firm investment and financial status. The Journal of Finance, v. LIV, n. 2, p. 673-692, 1999.

COELHO, Antônio Carlos Dias. Qualidade informacional e conservadorismo nos resultados contábeis publicados no Brasil. Tese de Doutorado, p. 249, 2007.

COELHO, Antonio Carlos Dias; LIMA, I. S. Consevadorismo nos resultados contábeis publicados no brasil: Comparação entre companhias de capital fechado e companhias de capital aberto. Revista Universo Contábil, v. 4, n. 2, p. 22-41, 2008.

COMITÊ DE PRONUNCIAMENTOS CONTÁBEIS. Pronunciamento Conceitual Básico (R1) - Estrutura Conceitual para Elaboração e Divulgação de Relatório Contábil-Financeiro. 2011.

DA COSTA, Fábio Moraes; LOPES, Alexsandro Broedel; DE OLIVEIRA COSTA, Alessandra Cristina. Conservadorismo em cinco países da América do Sul. Revista Contabilidade \& Finanças, v. 17, n. 41, p. 7-20, 2006.

DAVIDSON, Russell; MACKINNON, J. G. Estimation and Inference in Econometrics. New York: Oxford University Press, 1993.

DOS SANTOS, Luis Sérgio Ribeiro; DA COSTA, Fábio Moraes. Conservadorismo contábil e timeliness: evidências empíricas nas demonstrações contábeis de empresas brasileiras com ADRs negociados na Bolsa de Nova Iorque. Revista Contabilidade \& Finanças, v. 19, n. 48, p. 27-36, 2008.

DELOITE. IASB publishes revised Conceptual Framework. Disponível em: https://www.iasplus.com/en/news/2018/03/cf. Acessado em 03 jun. 2018.

DEMONIER, G. B.; ALMEIDA, J. E. F. DE; BORTOLON, P. M. O impacto das restrições financeiras na prática do conservadorismo contábil. Revista Brasileira de Gestão de Negócios, v. 17, p. 1264-1278, 2015.

FAZZARI, S.; HUBBARD, R. G.; PETERSEN, B. C. Financing constraints and corporate investment. Brookings papers on economic activity, p. 141-206, 1987.

GONZAGA, R. P.; COSTA, F. M. DA. A relação entre o conservadorismo contábil e os conflitos entre acionistas controladores e minoritários sobre as políticas de dividendos nas empresas brasileiras listadas na Bovespa. Revista Contabilidade \& Finanças, v. 20 , n. 50, p. 95-109, 2009.

HENDRIKSEN, E. S.; BREDA, M. F. V. Teoria da Contabilidade. São Paulo: Atlas, 1999.

HUIJGEN, Carel A; LUBBERINK, Martien Jan Peter. Liability exposure effects on earnings conservatism: The case of cross-listed firms. Lancaster University, Department of Accounting \& Finance Working Paper No. 2001/04. 2002.

IUDÍCIBUS, S. DE. Teoria da contabilidade. 9. ed. São Paulo: Atlas, 2009.

JUDGE, G. G.; GRIFFITHS, W.; LUTKEPOHL, H. The Theory and Practice of Econometrics. New York: Wiley, 1985.

LAFOND, R.; ROYCHOWDHURY, S. Managerial ownership and accounting conservatism. Journal of Accounting Research, v. 46 , n. 1 , p. $101-133,2008$.

LEE, Jimmy Kiat Bee. The role of accounting conservatism in firms' financial decisions. Research Collection School of Accountancy p. 1-46, 2012.

LI, X. Accounting conservatism and the cost of capital: An international analysis. Journal of Business Finance and Accounting, v. 42, n. 5-6, p. 555-582, 2015.

LOPES, A. B. A informação contábil e o mercado de capitais. Cengage Learning Editores, 2004.

PAULO, E. Manipulação das informações contábeis: Uma análise teórica e empírica sobre os modelos operacionais de detecção de gerenciamento de resultados (volume I). Tese de Doutorado, p. 260, 2007.

PAULO, E.; ANTUNES, M. T. P.; FORMIGONI, H. Conservadorismo contábil nas companhias abertas e fechadas brasileiras. Conservadorismo contábil nas companhias abertas e fechadas brasileiras, v. 48, p. 46-50, 2008.

PENMAN, S. H.; ZHANG, X.-J. Accounting conservatism, the quality of earnings, and stock returns. The Accouting Review, v. 77, n. 2, p. 237-264, 2002.

PROCIANOY, Jairo Laser; SCHNORRENBERGER, Adalberto. A influência da estrutura de controle nas decisões de estrutura de capital das companhias brasileiras. Revista Brasileira de Economia, v. 58, n. 1, p. 122-146, 2004.

RAUPP, Fabiano Maury; BEUREN, Ilse Maria. Metodologia da Pesquisa Aplicável às Ciências. Como elaborar trabalhos mono- 
gráficos em contabilidade: teoria e prática. São Paulo: Atlas, 2006.

SANTOS, E. S.; CALIXTO, L. Impactos do início da harmonização contábil internacional (Lei 11.638/07) nos resultados das empresas abertas. RAE eletrônica, v. 9, n. 1, p. 1-27, 2010.

WATTS, R. L. Conservatism in accounting part I: Explanations and implications. Accounting horizons v. 17, n. 3, p. 207-221, 2003.

WATTS, R. L.; ZIMMERMAN, J. L. Positive accounting theory : A ten year perspective. The Accouting Review, n. 65, p. 131$156,1990$.

WOOLDRIDGE, Jeffrey M. Econometric analysis of cross section and panel data. MIT press, 2010. 